\title{
Studies and Suggestions on English Vocabulary Teaching and Learning
}

\author{
Shigao Zheng \\ Foreign Languages School, China University of Petroleum, Beijing \\ 18 Fuxue Road, Changping District, Beijing 102249, China \\ E-mail: jeffzsg@126.com
}

Received: January 30, 2012

Accepted: February 12, 2012

Published: May 1, 2012

doi:10.5539/elt.v5n5p129

URL: http://dx.doi.org/10.5539/elt.v5n5p129

\begin{abstract}
To improve vocabulary learning and teaching in ELT settings, two questionnaires are designed and directed to more than 100 students and teachers in one of China's key universities. The findings suggest that an enhanced awareness of cultural difference, metaphorical competence, and learners' autonomy in vocabulary acquisition will effectively facilitate the vocabulary learning. Simultaneously, a teaching model is recommended based on the findings of this survey, which incorporates ideas advocated by cognitive linguistics. Class instruction on vocabulary learning strategies can help students gain awareness of learning strategies. The greater the strategy awareness of learners, the more likely they will be to use task-appropriate learning strategies that help them overcome their general learning style limitations, and the more likely that these strategies will assist in processing, retrieving, and using new language information.
\end{abstract}

Keywords: English vocabulary, Teaching, Learning, College students

\section{Introduction}

In a bid to find an effective and fruitful way to teach and learn English vocabulary for Chinese college students, the authors conduct a study in a Chinese university on the vocabulary teaching and learning. More than one hundred students and teachers were voluntarily involved in the study. All the students were non-English majors. The teachers involved in the study were the Foreign Languages School faculty members.

As teaching and learning is interactive, two questionnaires are designed in this study. Questionnaire I is for the students who were asked about their understanding and performance of vocabulary learning. Questionnaire II is for the teachers who were asked about their understanding and performance of vocabulary teaching. The objective is to get a quantized attitude and opinion of the teachers and students in terms of their vocabulary teaching and learning.

Questionnaire I was distributed to the students, while Questionnaire II was handed out to the teachers respectively. In order to help the subjects to understand the questions, every question in both questionnaires is dubbed in its Chinese translation. The students were required to fulfill the questionnaire in one class hour, while the teachers were expected to finish it in their spare time of the day. The answer sheets were collected after all subjects had finished them. 100 copies of student questionnaires and 20 copies of teacher questionnaires were sent out and 90 copies of student questionnaire and 19 copies of teacher questionnaires were completed, collected and analyzed.

The two questionnaires highlight the following three questions:

(1) How do the students and teachers understand vocabulary teaching/learning?

(2) What is the current situation of vocabulary teaching or learning in university?

(3)What are the problems the subjects think in their vocabulary teaching/learning?

All the questions are written in English. In bracket, Chinese versions for the questions are provided so that the subjects can understand the English questions well. All the questions are closed ones for the sake of the objectivity of the study. Therefore, quantitative approach is used to analyze the data collected from the two questionnaires.

\section{Findings of the Study}

\subsection{Students' Understanding of Vocabulary Learning}

The students offered various kinds of responses to the question about their understanding of vocabulary learning, which are summarized as in Table 1. 


\subsection{Teachers' Understanding of Vocabulary Teaching}

The teachers involved in this study also offered various kinds of responses to the question about their understanding of vocabulary teaching. (Table 2)

\subsection{Students' Performance in Their English Vocabulary Learning}

As for the questions about the current situation of vocabulary learning in university, the students' responses are summarized in Table 3.

\subsection{Teachers' Performance in Their English Vocabulary Teaching}

As for the questions about the situation of vocabulary teaching in university, the teachers offer responses in Table 4.

\section{Analysis and Discussion}

\subsection{Students' Understanding in Terms of English Vocabulary Learning}

More than 50\% students believe that vocabulary plays a very important role in language learning. 1/3 students claim that vocabulary holds an important position in language learning. Only $15 \%$ students argue that vocabulary is not important. The positive figures show that most students (85\%) are aware of the importance of vocabulary in English language learning.

$28 \%$ students think that vocabulary learning is to learn the pronunciation and spelling of words. $36 \%$ students say that vocabulary learning is to learn pronunciation, spelling, and the meaning in a word list. $24 \%$ students believe that learning vocabulary should learn collocations of words; and $11 \%$ students think that learning vocabulary should learn all the item-related meanings. These figures indicate that students have the idea to learn vocabulary because they know in order to acquire vocabulary, they have to learn the basics, e.g. pronunciation, spelling, and meanings of the words. $12 \%$ students think the difficulty in vocabulary learning is pronunciation. $22 \%$ claim that it is spelling, and $41 \%$ students think the learning of a word's meanings is the most difficult one. $25 \%$ students believe it is the collocation of words that is their headache.

$30 \%$ students hold that contexts in which words are used are helpful for vocabulary learning. $20 \%$ students believe that lexical knowledge (such as: suffix, root, and stem of words, etc.) is helpful for vocabulary learning. $27 \%$ students think that knowledge of Western cultures is helpful for their vocabulary learning. $8 \%$ students believe the society-related knowledge is helpful for their vocabulary learning. $6 \%$ students believe their mother language is helpful for their vocabulary learning. $8 \%$ students think the word collocation is helpful for their vocabulary learning. These responses indicate that the students have realized the importance of context and culture.

\subsection{Teachers' Understanding in Terms of Vocabulary Teaching}

The findings show that $36 \%$ teachers claim that vocabulary plays a very important role in language teaching. $60 \%$ teachers think that vocabulary plays an important role in language teaching while only less than $3 \%$ teachers don't think highly of the importance of vocabulary. The figures show that most teachers (97\%) involved in the study think that vocabulary teaching should be prioritized.

In the study, 58\% teachers think vocabulary teaching is to teach pronunciation, spelling and the meaning of the vocabulary in the word list; $15 \%$ teachers believe that in teaching vocabulary they should teach the different meanings of the same item in different contexts; $26 \%$ teachers claim vocabulary teaching should teach the collocations of the words. Those figures indicate that these teachers have been influenced by the traditional teaching methods in China. New words were taught by first reading them aloud and then by matching their translation in a word list.

More than half (55\%) state that the difficulty in vocabulary teaching is the meaning of vocabulary; $10 \%$ teachers believe that their difficulty in vocabulary teaching is the spelling of vocabulary; $26 \%$ teachers claim the collocation of vocabulary is the difficulty in vocabulary teaching; and $8 \%$ teachers think the pronunciation of vocabulary is the difficult one in their vocabulary teaching. The results show that for most teachers teaching the meaning of vocabulary is the most difficult one. It seems that teachers need to further explore the lexical system and semantic system of vocabulary and develop their vocabulary teaching if they want to teach the language well.

The figures show that $33 \%$ teachers believe that their culture knowledge is conducive to their vocabulary teaching; $29 \%$ teachers believe that the contexts in which words are used are conducive to their vocabulary teaching; $17 \%$ think their lexical knowledge is helpful; $9 \%$ think the collocation of vocabulary knowledge is useful; $6 \%$ think their society-related knowledge is helpful; and $4 \%$ teachers believe their mother language plays an important role in the vocabulary teaching. 


\subsection{The Students' Performance in Their English Vocabulary Learning}

From the answers to the questions, it can be inferred that most students favor the traditional methods such as learning vocabulary by reading repeatedly, learning vocabulary by writing automatically, learning vocabulary by analyzing affixes and roots, learning vocabulary by association, learning vocabulary by keeping word cards with pictures, photographs, objects, etc. Although those methods are easy to handle, yet most of them are not effective and systematic because the students usually learn vocabulary one by one according to the wordlist. Some methods, such as learning vocabulary by association and keeping word cards are time-consuming. Therefore the students need better methods to help them learn the vocabulary systematically.

As for the sixth question, 36\% students feel learning English vocabulary is a headache; $45 \%$ students feel learning English vocabulary is boring; $12 \%$ students feel learning English vocabulary is interesting; only $6.7 \%$ students feel learning English vocabulary is very interesting. From the figures, we can learn that most of the students lack interests in learning English vocabulary.

As for the efficiency of vocabulary learning, $48 \%$ students believe their vocabulary learning is not very efficient; $32 \%$ students think their vocabulary learning is inefficient; $11 \%$ subjects claim their vocabulary learning is efficient; and only $7.3 \%$ students are happy with their vocabulary learning. These figures show that majority of students (81\%) are not happy with their vocabulary learning.

\subsection{Teachers' Performance in Vocabulary Teaching}

As Table 4 shows the traditional teaching methods in China still hold important position in English vocabulary teaching. Those figures indicate that most of the teachers still employ traditional methods to teach vocabulary.

Nearly $30 \%$ teachers show interests in teaching vocabulary; $58 \%$ teachers think it is boring to teach vocabulary; and $13 \%$ teachers feel it is a headache to teach vocabulary. This result indicates that vocabulary teaching is troublesome for some teachers in foreign language teaching since most of the teachers (71\%) showed no interests in vocabulary teaching.

From the same table, it can be seen that $60 \%$ teachers feel that their vocabulary teaching is not very efficient; $26 \%$ teachers think their teaching of English vocabulary is efficient; $8 \%$ teaches believe their vocabulary teaching is inefficient; and only $5 \%$ teachers believe that their vocabulary teaching is very efficient. From those figures, it can be learnt that many teachers are not optimistic about the efficiency in their vocabulary teaching.

The above analysis indicates that teachers still prefer to use the traditional methods to teach vocabulary. The Grammar-Translation Method has been used as the primary method in foreign language teaching in China for a long time since it was introduced into the country in the early $20^{\text {th }}$ century.

As for their performance in learning/teaching vocabulary, it can be concluded that the traditional ways of teaching and learning vocabulary are still popular. English vocabulary teaching and learning in China reflected the fact that vocabulary instruction was dominated by the Grammar-Translation Method.

As for the teaching practice, the teachers apply some techniques to help the students to learn new vocabulary, such as: guessing from contexts, using word parts, using word cards, learning vocabulary through reading, listening and speaking, etc. Sometimes they also teach word collocations, different meanings of an item, grammar-related words and affixes, etc. Although all these techniques are helpful for the students, yet they only deal with the words in an isolated manner, and with corresponding Chinese meanings only.

With fragments of language learned through separate explanations of vocabulary in the class, students would find it difficult to learn and understand the new words, and the new words would be the obstacles in reading and understanding the text. As a result they would gradually lose their interests and become discouraged in learning English actively. It seems that the traditional mode can no longer effectively meet the needs of students. The teachers need some more effective methods to stimulate the students' interests in learning the vocabulary. Explaining the words one by one and learning words by memorizing the wordlist alone are boring, and the learners would lose interests in vocabulary learning after a while. The efficiency of vocabulary teaching/learning couldn't be satisfying without adequate methods and interests. So the existing problem is that a better teaching method is urgently needed to effectively enlarge the learners' vocabulary and enhance the learners' understanding of the lexical meanings so as to improve the efficiency of English vocabulary teaching and learning in the class.

\section{Suggestions for Vocabulary Teaching and Learning}

\subsection{Better Awareness of Differences between Two Cultures}

Understanding the cultural differences is an important component in teaching English vocabulary. It is certainly helpful for learners to understand and learn vocabulary if the teachers can introduce the different values or thinking 
of the people in different cultures. "Studying a language without knowing its culture is like knowing the shell without knowing its' content" (Hu W, 1988:1). Culture teaching and learning can undoubtedly enhance students' metaphorical competence which in turn will improve the learning of a language. So we should focus on the teaching of culture in English class to develop the learners' awareness of native speakers' way of thinking, and to really understand the meaning of words and use them appropriately.

Language, as well as the metaphors in the language, serves as the carrier to store and develop a culture, so there must be a lot of cultural elements in metaphors, especially in fresh metaphors. They are very dynamic and creative, and they are usually colored by a certain culture, especially by the history, religious beliefs and so on. For example, the literal meaning of "Godfather" is "a male who makes promises to help a Christian newly received into the church at the baptism ceremony" (Longman Dictionary of Contemporary English, 1987). Later, because of popularity of the movie titled The Godfather, its word meaning has been expanded: it now can refer to a person who is viewed as the most powerful or influential figure in an organization or community. Both the literal meaning and the metaphorical meaning are the product of the cultures. In China, where most people are non-religious, there is not such a metaphor, and therefore people may not know or understand what it means metaphorically.

There is no doubt that the teaching and learning of culture can enhance learners' metaphoric competence, upgrade their ability to comprehend metaphors, and in the long run will help them master the target language. The more we understand about the thinking, cognition of one culture, the more we understand its language, and its metaphors.

\subsection{Improvement of Metaphorical Competence on the Part of Students}

According to the cognitive science, metaphoric competence is a creative intellectual ability that improves as human's cognition develops. Metaphoric competence is a kind of developmental cognitive mapping ability to find meaning in metaphor. It is largely an unconscious strategy to analogize one object from one domain to another object in another domain. When one faces incompatible concepts, the cognitive competence mechanism is present to figure out the analogous relationship or produce metaphoric expressions. The better the students' metaphoric competence develops, the easier the students would feel in learning vocabulary and understanding lexical meanings.

Conceptual metaphor helps students change cognitive structure and thus extend their cognitive capacities. The macro-influence of metaphor on students lies in the fact that it highlights the sophistication of learning process. For the learners, learning is no longer a simple matter of the teacher's spoon-feeding and students' mechanical memorizing. The learners have to face the reality that the experience of the world is not direct as it is, but is always partially constituted by our modes of representation and understanding. They will realize that on some occasions learning is through changing the contexts of understanding and thus leading to new knowledge. The fact that people learn not only by changing experience to fit the concepts and modes of understanding as in the case of assimilation, but also by changing the concepts and modes of understanding to fit experience as in the case of accommodation that will be heuristic for students.

The students have a lot of cognitive abilities and schematic knowledge, which will facilitate the understanding of the target language. Schematic knowledge and cognitive abilities are evolved from our physical surroundings and they are also the basic knowledge for metaphorical mapping (Lakoff, 1993). The learners' previous knowledge and the schematic knowledge are very important for learners to learn more words. When meeting a new word, they can think about what they have already known about it, i.e. their previous knowledge and image schema, and link the new word with what they have already known to guess its meaning in the context. So it is necessary for the students to improve their own cultural consciousness and persist in implementing cultural education throughout the everyday lives. This is in perfect harmony with the essence of metaphor: understanding and experiencing one kind of thing in terms of another (Lakoff \& Johnson, 1980).

Therefore, students should be taught to enhance their awareness of the need in changing their cognitive structures, and learn some knowledge about schema, which will improve their cognitive competence. Conceptual metaphor is one way of performing the function of guiding cognitive changes for students and students themselves have to accommodate their cognitive structure and facilitate their cognitive abilities.

\subsection{More Autonomy in Learning Vocabulary on the Part of Students}

Teaching and learning are interactive. Yet most of the students fail to learn vocabulary independently due to the influences of the traditional teaching methods prevailing in China. In the traditional teacher-centered classroom, the teacher does too much of work and the students have less interest in learning vocabulary. The teacher is traditionally the knower, and the students are passive in learning. He/she reads for the students, and explains the text in a hair-splitting way for them. What the students have to do is to listen to the teacher and follow his/her mode of thinking and explanation. There's seldom any chance for them to learn autonomously. The students have been 
regarded as a bank to receive knowledge passively and the study process has been controlled by the teacher in schools and colleges. Some students are inclined to depend on their teachers too much in study from primary school through middle school to college. Therefore, how to overcome the psychological dependence of the students on the teacher is the challenge in promoting learner's autonomy in learning. Although they still need teachers' guidance and don't know much about the lexical system, they should have more confidence and autonomy in learning under the guidance of the teachers.

According to the conceptual metaphor, humans can always make full use of the known knowledge to understand the new knowledge, which can release their burden of memory while they are learning. Therefore, the teachers should help students to refine their views about their role in learning and create an environment for them to learn vocabulary independently by applying conceptual metaphor.

\section{Suggested Model for Teaching/Learning Vocabulary}

\subsection{Expanding Vocabulary by Mapping between Conceptual Domains}

Some psychologists hold that things in good order and meaningful groups have got greater chances to be memorized. Now that vocabulary is made up of a series of interrelated systems and is not just an arbitrary collection of items, there seems to be a clear case for presenting words in a systematic way that will both illustrate the organized nature of our mental lexicon and at the same time enable the students to internalize the items in a coherent way. The concept of one domain can be mapped onto another domain. So students can first memorize words in the same domain, and then use them to express a wider variety of concepts.

Let us take LOVE-IS-A-JOURNEY metaphor as an example. The knowledge about the domain of JOURNEY can be mapped onto the domain of LOVE. Therefore, we can learn words and terms about JOURNEY like crossroad, dead-end street, bumpy road, on the rock, milestone, separate way, etc, and put them into one meaning group. Then we map our understanding of these words and terms onto the target domain-LOVE, and we will get the same group of words but with different metaphorically extended meanings.

Since concept metaphors have a unique place in the formation of languages, the awareness of concept metaphors can help students accelerate the learning process and expand their vocabulary systematically in English.

\subsection{Acquiring Vocabulary on the Basis of Similarity}

Semantic motivation is a kind of psychological association, and it can explain the word's original meaning and other meaning-related items. As to many words in language, their metaphorical referents have certain similarity with their original meaning referents in their shape, function, characteristic, etc.

The word "crane", for instance, can refer to two different kinds of things: "large wading bird with long legs and neck" and "machine with a long arm that can be swung round, used for lifting and moving heavy weights". These kinds of bird and machine have similar shapes which have flexible long neck. The word "balance" not only refers to the two ends of the scale, but also refers to "the mental balance", "the balance of social development" and "the balance of economic development". "Cellular phone" is thus named because people found its key board is similar to the shape of "cell". The word "cock" can be used as a noun referring to a kind of domestic fowl and a noun referring to "the lifting or turning part of the body". We can find that the similarity lies in the shape of parts of their body.

The words that express the parts of body are mapped onto other concepts of scenery, plants, machines, language, economy, etc, which share similar shape or similar position, e.g. the limb of a river, a tongue of land, the bottom of a mountain, the breast of the mountain, the eye of a needle, the mouth of a volcano, the bosom of a mountain, the lap of a mountain, the bowels of the earth, the head of a Department, the joint of the bamboo, the arm of a crane, the back of a ship, the skeleton of the story, the backbone of society, the Voice of America, etc.

The words used to express actions, characters, feelings of human can also be used in other concept domains, e.g. "The hole yawned open in front of them.", "The pods of the beans are getting fat.", "The typewriter went crazy.", "The wind bellied out the sail.", "Our society is making great strides." etc.

\subsection{Learning Internal Relations between Language and Cognition}

Nowadays, more and more philosophers, psychologists, linguists and ethnologists attach importance to the internal relations between language and cognition. Human cognition of things gives an impetus to the changes in human psychology and promotes human cognition of the words used in the communicative language. In a sense, cognition is the result that human beings have brought about in perceiving and experiencing the outside world, and is the inevitable outcome of the interaction between human beings and the outside world. This shows the importance of the language expression is not only decided by its conceptual content but also by how the conceptual content is observed, perceived, and understood. Language is in the service of constructing and communicating meaning, and it 
provides the linguist and cognitive scientist with a window into the mind. Meanwhile, human's most important thinking activity is inevitably realized by language. Language is one of the human's smart intelligent activities, the inevitable outcome of the process of cognition, and the indication of human ability to recognize things. Different cognitive aspect leads to different metaphorical language.

Here is an example of language affected by cognition: Dragons and tigers are very ferocious and terrible. Anyone who enters dragon's pool or tiger's den would face life-and-death danger. In general, most people fear death, which is people's psychological reflection. Afterwards, a dangerous place of any kind is referred to as dragon's pool and tiger's den - a danger spot, and at the same time it is also taken as a psychological reflection.

\subsection{Learning Vocabulary Based on Embodied Experiences}

The recent developments in cognitive linguistics have revealed how abstract meaning in language is shaped by bodily experience. We can understand and express such concepts as time, causation, direction or love through metaphors that are shaped out of our sense as embodied creatures. Concepts, concrete or abstract, can not be arbitrary, but instead, are constructed in a metaphorical way. Meanwhile, the concepts can not be independent of mind's capability. They are based on human bodily experiences. Concepts are formed through body and mind's embodiment of the world and are understood through body and mind. (Lakoff \& Johnson, 1980) Meanings are on the embodied basis

For example, the heart's physical function of blood-pumping is strongly and noticeably affected by love, excitement, fear, and other strong emotions, therefore, the heart comes to symbolize some of those strong emotions, such as courage or passion. Because physical brightness is conductive to cheerfulness, "bright" comes to mean cheerful, while "dull" means the reverse. Likewise, emotional tension or feeling low can be linked to physical muscular states of tension or limpness which would accompany the relevant mental states. In English, some prepositions reveal how we infer concepts of spatial direction from the sense we have of our own bodies: The head leads the body. The head holds the eyes. Our eyes face forward and when we walk towards what they reveal, we move "ahead".

\subsection{Developing Vocabulary through Etymology}

Every word has its origin and its story of how it gets its current meanings. Because of its physical and meaningful origin, the etymology of a word is often found much easier to be comprehended than the bare linguistic symbol and its present semantic meanings. So whenever we teach an English word that is completely strange, we can ask students to look it up in a dictionary, or other reference books, and or surf on the Internet to find its origin. The interesting stories behind a word's birth can be a very good reminder for students to retrieve the related information. Take the word "handicap" for instance. "Handicap" is from the obsolete "hand in cap" (a game in which forfeits were held in a cap, for one who disobeys the rule, has to give forfeits to keep the equality of the game). Later, this word extends its meaning to a game called "handicap" which is a race or contest in which advantages or compensations are given different contestants to equalize the chances of winning. From learning the etymology of a word, students can improve their metaphorical cognitive abilities and learning the etymology of a word will certainly promote students' comprehension of new words.

The comparison of the use of metaphor in both languages can help the students understand and use idioms in English and help bridge the cultural gaps. It can also help students have a better understanding of idioms and activate their interest in the study of idioms and that of the language as a whole.

\subsection{Team Work}

Team work will be suggested for it is a motivating factor which can give students the chances to share the information they have and learn vocabulary independently. In teams, students can have a discussion about all the information and stories related to the words they've known, and can make full use of the known to explore the unknown by mapping. Students are expected to make positive comments on the new approach of vocabulary teaching. It is believed that the new teaching approach can activate learners' interests and enthusiasm of learning English vocabulary. In terms of the systematicity of vocabulary, it is believed that the new teaching method can help learners have a deep understanding of the word in terms of its polysemy. As for the teachers, it is expected that the new teaching approach can get students actively involved in the learning. It is hoped that both teachers and students will benefit a lot from the new teaching method since it is expected to be effective for vocabulary teaching and learning.

\section{Conclusion}

Vocabulary learning strategies facilitate word learning. Instruction in the use of appropriate word learning strategies is needed for the language learning process to be effective. Through instruction, word learning strategies will enable students to learn the target language vocabulary more efficiently, and to be able, eventually, to manage their own 
learning.

Class instruction on vocabulary learning strategies can help students gain awareness of learning strategies. The greater the strategy awareness of learners, the more likely they will be to use task-appropriate learning strategies that help them overcome their general learning style limitations, and the more likely that these strategies will assist in processing, retrieving, and using new language information. (Nyikos \& Oxford,1993)

\section{References}

Cameron, L., \& Low, G. (2001). Researching and Applying Metaphor. Shanghai: Shanghai Foreign Language Education Press.

Claire, K. (2000). Language and Culture. Shanghai: Shanghai Foreign Language Education Press.

Danesi, M. (1992). Language, Communication and Social Meaning. Washington, D.C.: Georgetown University Press.

Deignan, A., \& Salska, A. (1997). Teaching English metaphors using cross-linguistic awareness-raising activities. ELT Journal, Vo1.51, No.4. pp. 1-6.

Hu, W. (1988). Why Bother about Culture in ELT? Foreign Languages, No.4, pp. 1-6.

Jackendoff, R. (1983). Semantics and Cognition. Cambridge, MA: MTT Press.

Kang, H., \& Golden, A. (1994). Vocabulary Learning and Instruction in a Second or Foreign Language. International Journal of Applied Linguistics, $\quad$ No. $4, \quad$ pp. $57-77$. http://dx.doi.org/10.1111/j.1473-4192.1994.tb00055.x

Kittay, E. (1987). Metaphor: Its Cognitive Force and Linguistic Structure. Oxford: Oxford University Press.

Lakoff, G., \& Johnson, M. (1980). Metaphor We Live By. Chicago: The University of Chicago Press.

Lakoff, G. (1993). The contemporary theory of metaphor. Cambridge: Cambridge University Press.

Lazar, G. (1996). Using figurative language to expand students' vocabulary. ELT Journal, Vol.50, No. 1, pp. 60-67.

Nyikos, M., \& Oxford, R. (1993). A Factor Analytic Study of Language Learning Strategy Use: Interpretations from Information-Processing Theory and Social Psychology, Modern Language Journal, Vol. 77, pp. 11-22. http://dx.doi.org/10.1111/j.1540-4781.1993.tb01940.x

O'Malley, J. M., \& Chamot, A. U. (1990). Learning Strategies in Second Language Acquisition. Cambridge: Cambridge University Press.

Rubin,J., \& Thompson. I. (1982). How to Be a More Successful Language Learner. Boston: Heinle \& Heinle.

Shu, D. (2010). Reflection on the Contents and Methods of CET Classroom Teaching. Journal of The Foreign Language World, No.6, pp. 26-32.

\section{Author}

Shi-gao Zheng: male, born in 1976, lecturer of English with the School of Foreign Languages, China University of Petroleum. Attained M.A. in ELT in 2005. Specialize in English Language Teaching. Over 20 papers and books published. 
Table 1. Students' understanding of vocabulary learning

\begin{tabular}{|lc|}
\hline Question 1. In your opinion, what is the position of vocabulary in English learning? \\
Very important & $54 \%$ \\
Important & $31.3 \%$ \\
Not important & $14.7 \%$ \\
Question 2. What contents does vocabulary learning refer to? & $28 \%$ \\
Pronunciation and spelling of words & $36.7 \%$ \\
Pronunciation, spelling and the meaning in the word list & $24 \%$ \\
Collocations of words & $11.3 \%$ \\
All the meanings related to the item & $12 \%$ \\
Question 3. In your opinion, what is the difficulty in your vocabulary learning? \\
Pronunciation & $22 \%$ \\
Spelling & $41.3 \%$ \\
Meaning & $24.7 \%$ \\
Word collocations & 1 (earned is helpful for your \\
Question 4. In your opinion, what knowledge you have & \\
vocabulary learning?" & $20 \%$ \\
Lexical knowledge (suffix, root, and stem of words) & $30.4 \%$ \\
Contexts of word & $27.2 \%$ \\
Western Culture & $8 \%$ \\
Native language & $6 \%$ \\
Society-related knowledge & $8.4 \%$ \\
Word collocations &
\end{tabular}

Table 2. Teachers' understanding of vocabulary teaching

\begin{tabular}{|lc|}
\hline Question 1. In your opinion, what is the position of vocabulary in language teaching? \\
Very important & $36.8 \%$ \\
Important & $60.5 \%$ \\
Not important & $2.7 \%$ \\
Question 2. What contents does vocabulary teaching refer to? & $58.4 \%$ \\
Pronunciation, spelling and the meaning in the wordlist & $5 \%$ \\
Different meanings of an item in different contexts & $15.4 \%$ \\
Collocations of words & $26.2 \%$ \\
Question 3. In your opinion, what is the difficulty in your vocabulary teaching? & $7.8 \%$ \\
Pronunciation & $10.6 \%$ \\
Spelling & $55.3 \%$ \\
Meaning & $26.3 \%$ \\
Word collocations & \\
Question 4. In your opinion, what knowledge you have 1 learned is helpful for your \\
vocabulary teaching? \\
Lexical knowledge & $17.3 \%$ \\
Contexts of vocabulary & $29.3 \%$ \\
Cultures & $33.4 \%$ \\
Society-related knowledge & $6.7 \%$ \\
Native language & $4 \%$ \\
Word collocations & $9.3 \%$ \\
\hline
\end{tabular}


Table 3. Students' performance in their English vocabulary learning

\begin{tabular}{lc|}
\hline Question 5. "How do you usually learn vocabulary?" \\
By reading repeatedly & $28.4 \%$ \\
By writing automatically & $34.8 \%$ \\
By analyzing affixes and roots & $23.6 \%$ \\
By association & $10.8 \%$ \\
By keeping word cards with pictures, photographs, objects, etc. & $2.4 \%$ \\
\multicolumn{2}{c}{ Question 6. How do you feel learning English vocabulary? } \\
Headache & $36 \%$ \\
Boring & $45.3 \%$ \\
Interesting & $12 \%$ \\
Very interesting & $6.7 \%$ \\
Question 7. How do you feel your efficiency in vocabulary learning? \\
Inefficient & $32.7 \%$ \\
Not very efficient & $48.7 \%$ \\
Efficient & $11.3 \%$ \\
Very efficient & $7.3 \%$ \\
\hline
\end{tabular}

Table 4. Teachers' performance in their English vocabulary teaching

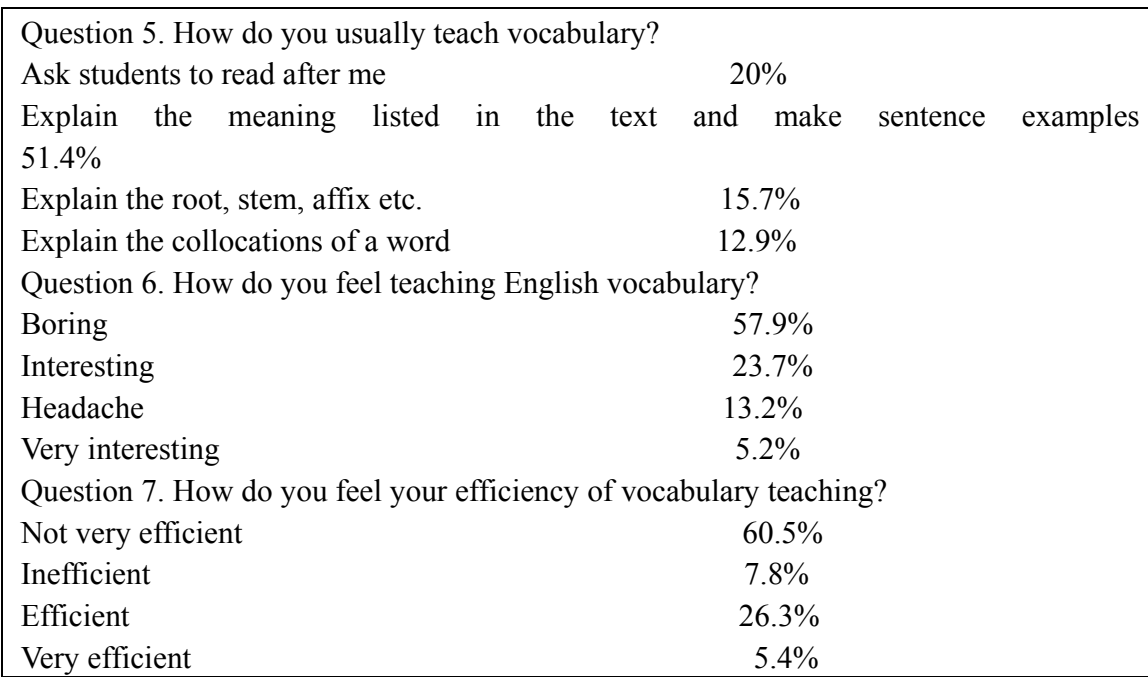

